\title{
Analisa Perbandingan Quality Of Service Antara Protokol PPTP dan L2TP Pada Virtual Private Network Berbasis Router Mikrotik
}

\author{
Dahnial $^{1)}$ \\ ${ }^{1)}$ Program Studi Ilmu Administrasi Negara STIA Satya Negara \\ Jl. Sukarejo, sukatani, Kenten. Palembang \\ Email :dahnialdp@yahoo.com ${ }^{1)}$
}

\begin{abstract}
The internet as a data transmission backbone has security threats in sending data. To overcome the security problem of every data communication that is done through a public network (public network), then a connection is needed that requires a connection between workstations running privately, so that only workstations that have access can connect, by using a virtual private network or VPN. The advantage of a VPN is that data sent over an encrypted VPN is quite safe and the secret is maintained even through the internet network because the data sent will go through the tunnel. Tunneling itself is a method for transferring data from one network to another by using a veiled internet network. Two protocols can be chosen in a VPN, namely Point to Point Tunneling Protocol (PPTP) and Layer 2 Tunneling Protocol (L2TP). However, the performance of each of these protocols is unknown yet. To find out the performance of the two protocols we need a test with a simulation method. Using a Mikrotik router and Wireshark application with Quality of Service $(Q o S)$ parameters consisting of Packet Loss, Delay, and Throughput on 2 clients connected to the mikrotik router and each client uses a different protocol. All clients will stream videos simultaneously to get a data packet capture. The test results will be grouped into four categories, namely bad, moderate, good and very good. It is expected that data will be able to show the quality of service of both protocols. so that it can be used as a reference in the selection of VPN protocol to be used.
\end{abstract}

Keywords: Quality of Service, PPTP, L2TP

\begin{abstract}
ABSTRAK
Internet sebagai backbone pengiriman data memiliki ancaman keamanan dalam pengiriman data. Untuk mengatasi masalah keamanan setiap komunikasi data yang dilakukan melalui jaringan publik (public network) maka diperlukan suatu mekanisme yang memungkinkan koneksi antar workstation berjalan secara private, sehingga hanya workstation yang memiliki akses yang dapat saling terhubung, dengan cara memanfaatkan virtual private network atau VPN. Keuntungan VPN adalah data yang dikirimkan melalui VPN terenkripsi sehingga cukup aman dan rahasianya tetap terjaga meskipun melalui jaringan internet, karena data yang dikirim akan melalui tunnel. Tunneling sendiri merupakan metode untuk transfer data dari suatu jaringan ke jaringan lain dengan memanfaatkan jaringan internet secara terselubung. Terdapat dua protokol yang dapat dipilih dalam VPN yaitu Point to Point Tunneling Protocol (PPTP) dan Layer 2 Tunneling Protocol (L2TP). Akan tetapi belum diketahui performa dari masing - masing protokol tersebut. Untuk mengetahui kinerja dari kedua protokol tersebut diperlukan sebuah pengujian dengan metode simulasi. Menggunakan router mikrotik dan aplikasi Wireshark dengan parameter Quality of Service (QoS) yang terdiri dari Packet Loss, Delay, dan Throughtput pada 2 client yang terhubung ke router mikrotik dan setiap client akan menggunakan protokol yang berbeda. Semua client akan melakukan video streaming secara bersamaan untuk mendapatkan capture paket data. Hasil pengujian akan dikelompokkan menjadi empat kategori, yaitu kategori buruk, sedang, bagus dan sangat bagus. Diharapkan akan dihasilkan sebuah data yang dapat menunjukkan kualitas dari layanan kedua protokol tersebut. sehingga dapat dijadikan acuan dalam pemilihan protokol vpn yang akan digunakan.
\end{abstract}

Kata kunci: Quality of Service, PPTP, L2TP 


\section{Pendahuluan}

Keamanan dari aliran data merupakan sebuah kewajiban dalam sebuah sistem yang berbasis jaringan internet. Saat ini banyak organisasi yang menjadikan jaringan internet sebagai backbone pengiriman data, karena kecepatan dan dari sisi biaya lebih murah.

Akan tetapi permasalahan keamanan masih menjadi factor utama. Informasi memang dapat disampaikan dengan mudah, akan tetapi masih ada kemungkinan informasi tersebut bocor ke tangan orang yang tidak bertanggungjawab.

Karena internet sendiri merupakan jaringan publik yang bisa menghubungkan siapa saja kedalam jaringan yang sangat besar, dan tentunya terdapat ancaman ancaman pencurian data didalamnya.

Untuk mengatasi masalah keamanan setiap komunikasi data yang dilakukan melalui jaringan publik (public network) maka diperlukan suatu mekanisme yang memungkinkan koneksi antar workstation berjalan secara private, sehingga hanya workstation yang memiliki akses yang dapat saling terhubung, dengan cara memanfaatkan virtual private network atau VPN.

VPN merupakan suatu sistem yang menghubungkan antara satu jaringan dengan jaringan lain secara pribadi melalui jaringan internet (publik). VPN adalah teknologi komunikasi yang memungkinkan seorang pegawai yang berada di dalam kantor terkoneksi ke jaringan publik dan menggunakannya untuk bergabung dalam jaringan lokal, mendapatkan hak dan pengaturan yang sama ketika pegawai berada di kantor (hisyam, 2019).

Keuntungan VPN adalah data yang dikirimkan melalui VPN terenkripsi sehingga cukup aman dan rahasianya tetap terjaga meskipun melalui jaringan internet. VPN memiliki beberapa protokol yang dapat digunakan, diantaranya Point to Point Tunneling Protocol (PPTP) dan Layer 2 Tunneling Protocol (L2TP). Teknologi jaringan PPTP (Point To Point Tunneling Protocol) merupakan pengembangan dari remote access point to point Protocol yang dikeluarkan oleh internet Engineering Task Force (IETF). PPTP merupakan Protocol jaringan yang merubah paket PPP menjadi IP datagram agar dapat ditransmisi melalui internet. PPTP juga dapat digunakan pada jaringan private LAN to LAN. Sedangkan L2TP (Layer 2 Tunneling Protocol) adalah sebuah tunneling Protocol yang memadukan dan mengkombinasikan dua buah tunneling Protocol yaitu L2F (Layer 2 Forwarding) milik cisco sistem dengan PPTP (Point To Point Tunneling Protocol) milik mikrosoft (Rendra, 2013).

Tunneling sendiri merupakan metode untuk transfer data dari suatu jaringan ke jaringan lain dengan memanfaatkan jaringan internet secara terselubung. Tunneling adalah cara di mana data ditransfer antara dua jaringan dengan aman. Semua data yang ditransfer difragmentasi menjadi paket atau bingkai yang lebih kecil dan kemudian melewati terowongan. Setiap frame yang melewati tunel akan dienkripsi dengan lapisan tambahan enkripsi dan enkapsulasi tunneling, yang juga digunakan untuk merutekan paket ke arah yang benar.
Enkapsulasi ini kemudian akan dikembalikan ke tujuan dengan dekripsi data, yang kemudian dikirim ke simpul tujuan yang diinginkan (onno, 2000). Koneksi point to point ini sesungguhnya tidak benar-banar ada, namun data yang dihantarkanya terlihat seperti benar-benar melewati koneksi pribadi yang bersifat point to point (budiadji, 2009) .

Pada penelitian ini akan dilakukan analisis perbandingan performa Point to Point Tunneling Protocol dan Layer 2 Tunneling Protocol pada jaringan VPN untuk mengetahui pengaruh penggunaan protokol VPN terhadap performa Quality of Service (QoS). Performa yang dimaksud meliputi parameter delay, throughput, dan packet loss.

QoS merupakan kualitas atau jaminan terhadap layanan (service) yang diberikan kepada pengguna jaringan. Jaminan yang diberikan duantaranya adalah faktor kegagalan sistem, keamanan jaringan dan stabilitas jarungan. Sehingga dengan adanya jaminan yang diberikan pengguna akan merasa nyaman dengan layanan yang digunakan (rendra, 2015).

Pengujian perlu dilakukan untuk mengetahui protokol manakah yang menghasilkan performa terbaik pada jaringan VPN. Hal ini dianggap penting karena VPN melakukan proses enkripsi dan deskripsi terhadap setiap paket data yang dikirimkan, sehingga akan berpengaruh terhadap performa jaringan dikarenakan proses tersebut membutuhkan waktu lebih. Dengan latar belakang tersebut penulis bermaksud memberikan data perbandingan performa protokol VPN agar dapat dijadikan salah satu referensi dalam perancangan sebuah jaringan VPN.

\section{A. Metode Penelitian}

Metode yang digunakan dalam penelitian ini menggunakan metode kualitatif dimana peneliti menjadi alat utama dalam pengumpulan data ${ }^{[6]}$. Pengumpulan data yang peneliti lakukan dengan cara mencari referensi yang terkait dengan topik penelitian dari jurnal maupun buku. Dengan cara tersebut peneliti dapat memahami cara kerja dari teknik maupun metode yang dipakai, sehingga diharapkan dalam pengembangan sistem nantinya akan berjalan dengan baik dan lancar.

Selain itu dalam penelitian ini penulis juga menggunakan metode penelitian komparatif yaitu membandingkan kinerja dari dua protokol VPN dengan membuat model simulasi berupa konfigurasi VPN PPTP dan L2TP yang diaktifkan secara bersamaan pada 2 (dua) komputer client dengan melakukan streaming video untuk mendapatkan capture paket data. Dan dalam pembuatan model simulasi, spesifikasi kebutuhan perangkat keras dan perangkat lunak yang peneliti gunakan dalam penelitian ini, seperti pada tabel 1 dibawah ini:

Tabel 1. Perangkat yang digunakan

\begin{tabular}{|c|l|}
\hline $\begin{array}{c}\text { Perangkat } \\
\text { Lunak }\end{array}$ & \multicolumn{1}{|c|}{ Perangkat Keras } \\
\hline Windows 8.1 Pro & $\begin{array}{l}\text { Laptop dengan Spesifikasi: } \\
\text { Processor A8-4500M up to }\end{array}$ \\
\hline
\end{tabular}




\begin{tabular}{|l|l|}
\hline \multirow{2}{*}{$\begin{array}{l}\text { Winbox Loader } \\
\text { versi 2.2.18 }\end{array}$} & $\begin{array}{l}\text { HD8750 2GB Vram, RAM } \\
\text { 4GB, HDD 500GB }\end{array}$ \\
\hline \multirow{5}{*}{ Wireshark v.2.5.1 } & $\begin{array}{l}\text { Laptop dengan spesifikasi } \\
\text { Processor core i3-6006U, Ram } \\
\text { 4GB, HDD 1TB, GPU }\end{array}$ \\
& $\begin{array}{l}\text { NVIDIA GeForce MX110 } \\
\text { With 2GB VRAM }\end{array}$ \\
\cline { 2 - 2 } & $\begin{array}{l}\text { Router RB1100AHx4 1U } \\
\text { Rackmount dengan } \\
\text { Spesifikasi: processor Alpine } \\
\text { AL21400 1.4GHz Quad Core, } \\
\text { 1GB RAM, routerOS level 6, }\end{array}$ \\
\hline
\end{tabular}

Sedangkan topologi jaringan yang peneliti gunakan dalam simulasi ini terlihat seperti gambar 1 dibawah ini :

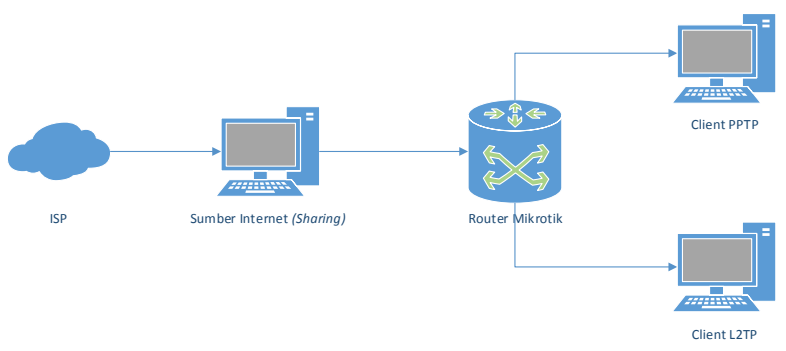

Gambar 1. Topologi Simulasi

Penelitian ini menggunakan pengujian pada konektivitas VPN. Pengujian akan dilakukan melalui komputer client terhadap jaringan VPN. Pengujian meliputi performa yaitu throughtput, delay, dan packet loss dengan menggunakan aplikasi wireshark untuk melakukan capture paket data yang selanjutnya akan digunakan untuk mendapatkan nilai masing-masing parameter. Adapun perhitungan nilai serta kategori masing-masing parameter adalah sebagai berikut :

1. Throughput

Throughput yaitu kecepatan (rate) trensfer data efektif diukur dalam bps. Throughput merupakan jumlah total kedatangan paket yang sukses yang diamati pada tujuan selama intervel waktu tertentu dibagi oleh durasi interval waktu tersebut (Yanto, 2013). Berikut merupakan nilai throughput berdasarkan (Prihatin, 2016).

Tabel 2. Tabel Throughput

\begin{tabular}{|c|c|c|}
\hline $\begin{array}{c}\text { Kategori } \\
\text { Throughput }\end{array}$ & Throughput & Indeks \\
\hline Sangat Bagus & $100 \%$ & 4 \\
\hline Bagus & $75 \%$ & 3 \\
\hline Sedang & $50 \%$ & 2 \\
\hline Buruk & $<25 \%$ & 1 \\
\hline
\end{tabular}

Persamaan perhitungan Throughtput throughput: $\quad$ paket data yang diterima

2. Delay

Delay adalah waktu yang dibutuhkan data untuk menempuh jarak dari asal ke tujuan. Delay dapat

dipengaruhi oleh jarak, media fisik kongesti atau juga waktu proses lama (Yanto, 2013).. Berikut merupakan nilai delay berdasarkan (Prihatin, 2016).

Tabel 3. Tabel Delay

\begin{tabular}{|c|c|c|}
\hline Kategori Delay & Besar Delay & Indeks \\
\hline Sangat Bagus & $<150 \mathrm{~ms}$ & 4 \\
\hline Bagus & $150 \mathrm{s.d} 300 \mathrm{~ms}$ & 3 \\
\hline Sedang & $300 \mathrm{s.d} 450 \mathrm{~ms}$ & 2 \\
\hline Buruk & $>450 \mathrm{~ms}$ & 1 \\
\hline
\end{tabular}

Persamaan perhitungan Delay

delay: $\frac{\text { lama pengamatan }}{\text { total paket yang diterima }}$

\section{Packet Loss}

Merupakan suatu parameter yang menggambarkan suatu kondisi yang menunjukan jumlah total paket yang hilang, dapat terjadi karena collision dan congestion pada jaringan (Yanto, 2013). Berikut merupakan nilai packet loss berdasarkan (Prihatin, 2016) .

Tabel 3. Tabel Packet Loss

\begin{tabular}{|c|c|c|}
\hline $\begin{array}{c}\text { Kategori } \\
\text { Packet Loss }\end{array}$ & Packet Loss & Indeks \\
\hline Sangat Bagus & $0 \%$ & 4 \\
\hline Bagus & $3 \%$ & 3 \\
\hline Sedang & $15 \%$ & 2 \\
\hline Buruk & $25 \%$ & 1 \\
\hline
\end{tabular}

Persamaan perhitungan Packet Loss

$\frac{(\text { Paket terkirim - Paket diterima) X } 100 \%}{\text { Paket yang dikirim }}$ Paket yang dikirim

\section{Hasil dan Pembahasan}

Pada bagian ini akan dibahas implementasi dalam simulasi dalam bentuk berupa tangkapan layar dari hasil pengujian sistem.

\section{A. Pengujian Qos dengan PPTP}

Untuk mendapatkan capture paket data, pada wireshark klik menu Analysis $=>$ Summary.

Traffic

Packets

Between first and last packet $304,918 \mathrm{sec}$

Avg. packets/sec

Avg. packet size

Bytes

Gambar 2. Summary Wireshark percobaan 1 PPTP 


$\begin{array}{lll}\text { Traffic } & \text { Captured } & \text { Displayed } \\ \text { Packets } & 37879 & 37879 \\ \text { Between first and last packet } & 605,885 \mathrm{sec} & \\ \text { Avg. packets/sec } & 62,518 \\ \text { Avg. packet size } & 738,862 \text { bytes } \\ \text { Bytes } & 27987348 \\ \text { Avg. bytes/sec } & 46192,484\end{array}$

Gambar 3. Summary Wireshark percobaan 2 PPTP

Setelah data summary didapatkan, maka dilakukan perhitungan nilai pada masing - masing parameter QoS sebagai berikut :

1. Perhitungan Throughtput

Data throughtput diperoleh melalui pengamatan menggunakan tools wireshark. Data tersebut adalah sebagai berikut :

Tabel 4. Data Throughtput PPTP

\begin{tabular}{|c|c|c|}
\hline $\begin{array}{c}\text { Percobaan } \\
\text { ke- }\end{array}$ & $\begin{array}{c}\text { Paket data yang } \\
\text { diterima (Byte) }\end{array}$ & $\begin{array}{c}\text { Lama } \\
\text { Pengamatan } \\
\text { (Second) }\end{array}$ \\
\hline 1 & 19568571 & 304,918 \\
\hline 2 & 27987348 & 605,885 \\
\hline
\end{tabular}

Data yang diperolah selanjutnya dihitung menggunakan persamaan throughtput :

\section{Percobaan 1 :}

$$
\begin{aligned}
& =\frac{\text { paket data yang diterima }}{\text { lama pengamatan }} \\
& =\quad(19568571 / 304,918) \\
& =\quad(64176,503 \mathrm{Bps} * 8) / 1024 \\
& =\quad 501,379 \mathrm{Kbps}
\end{aligned}
$$

Throughput $(\%)=(501,379 / 1024) * 100 \%$

$$
=48,96 \%
$$

\section{Percobaan 2 :}

$$
\begin{aligned}
& =\text { paket data yang diterima } \\
& \text { lama pengamatan } \\
& =(27987348 / 605,885) \\
& =(46192,508 \mathrm{Bps} * 8) / 1024 \\
& =360,879 \mathrm{Kbps}
\end{aligned}
$$

$$
\begin{aligned}
\text { Throughput }(\%)= & (360,879 / 1024) * 100 \% \\
= & \mathbf{3 5 , 2 4} \%
\end{aligned}
$$

Berdasarkan perhitungan di atas, maka hasil perhitungan nilai throughput dapat dikategorikan sebagai berikut :

Tabel 5. Hasil Perhitungan Throughtput PPTP

\begin{tabular}{|c|c|c|}
\hline $\begin{array}{c}\text { Percobaan } \\
\text { ke- }\end{array}$ & $\begin{array}{c}\text { Nilai } \\
\text { Throughtput }\end{array}$ & Kategori \\
\hline 1 & $48,96 \%$ & Sedang \\
\hline 2 & $35,24 \%$ & Sedang \\
\hline
\end{tabular}

2. Perhitungan Delay

Data Delay diperoleh melalui pengamatan menggunakan tools wireshark. Data tersebut adalah sebagai berikut :

Tabel 6. Data Delay PPTP

\begin{tabular}{|c|c|c|}
\hline $\begin{array}{c}\text { Percobaan } \\
\text { ke- }\end{array}$ & $\begin{array}{c}\text { Lama } \\
\text { Pengamatan } \\
\text { (Second })\end{array}$ & Total Paket \\
\hline 1 & $304,918 \mathrm{~s}$ & 24596 \\
\hline 2 & $605,885 \mathrm{~s}$ & 37879 \\
\hline
\end{tabular}

Data yang diperolah selanjutnya dihitung menggunakan persamaan delay:

Percobaan 1 :

$$
\begin{aligned}
& =\frac{\text { lama pengamatan }}{\text { total paket yang diterima }} \\
& =304,918 / 24596 \\
& =0,01239 \mathrm{~s} * 1000=\mathbf{1 2 , 3 9} \mathbf{~} \mathbf{s}
\end{aligned}
$$

\section{Percobaan 2:}

$=$ lama pengamatan

total paket yang diterima

$=605,885 / 37879$

$=0,015995 \mathrm{~s} * 1000=\mathbf{1 5 , 9 9 2} \mathbf{~ m s}$

Berdasarkan perhitungan di atas, maka hasil perhitungan nilai delay dapat dikategorikan sebagai berikut

Tabel 7. Hasil Perhitungan Delay PPTP

\begin{tabular}{|c|c|c|}
\hline Percobaan ke- & Nilai Delay & Kategori \\
\hline 1 & $12,39 \mathrm{~ms}$ & Sangat Bagus \\
\hline 2 & $15,992 \mathrm{~ms}$ & Sangat Bagus \\
\hline
\end{tabular}

3. Perhitungan Packet Loss

Data Packet Loss diperoleh melalui pengamatan menggunakan tools wireshark. Data tersebut adalah sebagai berikut :

Tabel 8. Data Packet Loss PPTP

\begin{tabular}{|c|c|c|}
\hline Percobaan ke- & $\begin{array}{c}\text { Paket Data } \\
\text { Terkirim }\end{array}$ & $\begin{array}{c}\text { Paket Data } \\
\text { Diterima }\end{array}$ \\
\hline 1 & 24596 & 24596 \\
\hline 2 & 37879 & 37879 \\
\hline
\end{tabular}

Data yang diperolah selanjutnya dihitung menggunakan persamaan packet loss :

Percobaan 1 :

$=$ (Paket data terkirim-Paket data diterima)X $100 \%$ Paket data yang dikirim $=\frac{(24596-24596) \times 100 \%}{24596}=0 \%$

\section{Percobaan 2 :}

$=($ Paket data terkirim-Paket data diterima $) X 100 \%$

Paket data yang dikirim

$=(37879-37879) \times 100 \%=0 \%$ 
Berdasarkan perhitungan di atas, maka hasil perhitungan nilai packet loss dapat dikategorikan sebagai berikut :

Tabel 9. Hasil Perhitungan Packet Loss PPTP

\begin{tabular}{|c|c|c|}
\hline $\begin{array}{c}\text { Percobaan } \\
\text { ke- }\end{array}$ & Nilai Packet Loss & Kategori \\
\hline 1 & $0 \%$ & Sangat Bagus \\
\hline 2 & $0 \%$ & Sangat Bagus \\
\hline
\end{tabular}

\section{B. Pengujian Qos dengan L2TP}

Untuk mendapatkan capture paket data, pada wireshark klik menu Analysis $=>$ Summary.

\begin{tabular}{|c|c|c|}
\hline 1 & Captured & Displayed I \\
\hline Packets & 14483 & 14483 \\
\hline Between first and last packet & $306,381 \mathrm{sec}$ & \\
\hline Avg. packets/sec & 47,271 & \\
\hline Avg. packet size & 863,091 bytes & \\
\hline Bytes & 12500149 & \\
\hline Avg. bytes/sec & 40799,358 & \\
\hline
\end{tabular}

Gambar 4. Summary Wireshark percobaan 1 L2TP

\begin{tabular}{|l|l|l|}
\hline Traffic & Captured I & Displayed I \\
\hline Packets & 24373 & 24373 \\
Between first and last packet & $600,876 \mathrm{sec}$ \\
Avg. packets/sec & 40,562 \\
Avg. packet size & 843,138 bytes \\
Bytes & 20549805 \\
Avg. bytes/sec & 34199,763 \\
\hline
\end{tabular}

Gambar 5. Summary Wireshark percobaan 2 L2TP

Setelah data summary didapatkan, maka dilakukan perhitungan nilai pada masing-masing parameter QoS sebagai berikut :

1. Perhitungan Throughtput

Data throughtput diperoleh melalui pengamatan menggunakan tools wireshark. Data tersebut adalah sebagai berikut :

Tabel 10. Data Throughtput L2TP

\begin{tabular}{|c|c|c|}
\hline $\begin{array}{c}\text { Percobaan } \\
\text { ke- }\end{array}$ & $\begin{array}{c}\text { Paket data yang } \\
\text { diterima (Byte) }\end{array}$ & $\begin{array}{c}\text { Lama } \\
\text { Pengamatan } \\
\text { (Second) }\end{array}$ \\
\hline 1 & 12500149 & 306,381 \\
\hline 2 & 20549805 & 600,876 \\
\hline
\end{tabular}

Data yang diperolah selanjutnya dihitung menggunakan persamaan throughtput :

\section{Percobaan 1}

= paket data yang diterima

lama pengamatan

$=(12500149 / 306,381)$

$=(40799,361 \mathrm{Bps} * 8) / 1024$

$=308,745 \mathrm{Kbps}$

Throughput $(\%)=(308,745 / 1024) * 100 \%$

$$
=31,13 \%
$$

\section{Percobaan 2}

= paket data yang diterima

lama pengamatan

$=(20549805 / 600,876)$

$=(34199,743 \mathrm{Bps} * 8) / 1024$

$=267,185 \mathrm{Kbps}$

Throughput $(\%)=(267,185 / 1024) * 100 \%$ $=\mathbf{2 6 , 0 9 \%}$

Berdasarkan perhitungan di atas, maka hasil perhitungan nilai throughput dapat dikategorikan sebagai berikut :

Tabel 11. Hasil Perhitungan Throughtput L2TP

\begin{tabular}{|c|c|c|}
\hline $\begin{array}{c}\text { Percobaan } \\
\text { ke- }\end{array}$ & Nilai Throughtput & Kategori \\
\hline 1 & $31,13 \%$ & Sedang \\
\hline 2 & $26,09 \%$ & Sedang \\
\hline
\end{tabular}

2. Perhitungan Delay

Data Delay diperoleh melalui pengamatan menggunakan tools wireshark. Data tersebut adalah sebagai berikut :

Tabel 12. Data Delay L2TP

\begin{tabular}{|c|c|c|}
\hline $\begin{array}{c}\text { Percobaan } \\
\text { ke- }\end{array}$ & $\begin{array}{c}\text { Lama Pengamatan } \\
\text { (Second) }\end{array}$ & $\begin{array}{c}\text { Total } \\
\text { Paket }\end{array}$ \\
\hline 1 & $306,381 \mathrm{~s}$ & 14483 \\
\hline 2 & $600,876 \mathrm{~s}$ & 24373 \\
\hline
\end{tabular}

Data yang diperolah selanjutnya dihitung menggunakan persamaan delay:

Percobaan 1

= lama pengamatan

total paket yang diterima

$=306,381 / 14483$

$=0,02115 \mathrm{~s} * 1000=\mathbf{2 1 , 1 5} \mathbf{~ m s}$

\section{Percobaan 2}

= lama pengamatan

total paket yang diterima

$=600,876 / 24373$

$=0,02465 \mathrm{~s} * 1000=\mathbf{2 4 , 6 5} \mathbf{~ m s}$

Berdasarkan perhitungan di atas, maka hasil perhitungan nilai delay dapat dikategorikan sebagai berikut :

Tabel 13. Hasil Perhitungan Delay L2TP

\begin{tabular}{|c|c|c|}
\hline $\begin{array}{c}\text { Percobaan } \\
\text { ke- }\end{array}$ & Nilai Delay & Kategori \\
\hline 1 & $21,15 \mathrm{~ms}$ & Sangat Bagus \\
\hline 2 & $24,65 \mathrm{~ms}$ & Sangat Bagus \\
\hline
\end{tabular}

3. Perhitungan Packet Loss

Data Packet Loss diperoleh melalui pengamatan menggunakan tools wireshark. Data tersebut adalah sebagai berikut : 
Tabel 14. Data Packet Loss L2TP

\begin{tabular}{|c|c|c|}
\hline $\begin{array}{c}\text { Percobaan } \\
\text { ke- }\end{array}$ & $\begin{array}{c}\text { Paket Data } \\
\text { Terkirim }\end{array}$ & $\begin{array}{c}\text { Paket Data } \\
\text { Diterima }\end{array}$ \\
\hline 1 & 14483 & 14483 \\
\hline 2 & 24373 & 24373 \\
\hline
\end{tabular}

Data yang diperolah selanjutnya dihitung menggunakan persamaan packet loss :

\section{Percobaan 1}

$=($ Paket data terkirim - Paket data diterima $) X 100 \%$

$$
\text { Paket data yang dikirim }
$$

$=(14483-14483) \times 100 \%=0 \%$

$$
14483
$$

\section{Percobaan 2}

$=\underline{(24373-24373) \times 100 \%=0 \%}$

$$
24373
$$

Berdasarkan perhitungan di atas, maka hasil perhitungan nilai packet loss dapat dikategorikan sebagai berikut :

Tabel 15. Hasil Perhitungan Packet Loss L2TP

\begin{tabular}{|c|c|c|}
\hline $\begin{array}{c}\text { Percobaan } \\
\text { ke- }\end{array}$ & Nilai Packet Loss & Kategori \\
\hline 1 & $0 \%$ & Sangat Bagus \\
\hline 2 & $0 \%$ & Sangat Bagus \\
\hline
\end{tabular}

Berdasarkan hasil perhitungan pada masing masing protokol, maka didapat hasil perbandingan kategori dan nilai throughtput, delay, dan packet loss sebagai berikut :

Tabel 16. Perbandingan Kategori Parameter QoS

\begin{tabular}{|c|c|c|c|}
\hline \multirow{2}{*}{ No } & \multirow{2}{*}{$\begin{array}{c}\text { Parameter } \\
\text { QoS }\end{array}$} & \multicolumn{3}{|c|}{ PPTP } \\
\cline { 3 - 4 } 2 & Throughtput & Sercobaan 1 & Percobaan 2 \\
\hline 2 & Delay & Sangat Bagus & $\begin{array}{c}\text { Sangat } \\
\text { Bagus }\end{array}$ \\
\hline 3 & Packet Loss & Sangat Bagus & $\begin{array}{c}\text { Sangat } \\
\text { Bagus }\end{array}$ \\
\hline No & $\begin{array}{c}\text { Parameter } \\
\text { QoS }\end{array}$ & \multicolumn{2}{|c|}{ L2TP } \\
\cline { 3 - 4 } 1 & Throughtput & Sedang & Sedang \\
\hline 2 & Delay & $\begin{array}{c}\text { Sangat } \\
\text { Bagus }\end{array}$ & Sangat Bagus \\
\hline 3 & Packet Loss & $\begin{array}{c}\text { Sangat } \\
\text { Bagus }\end{array}$ & Sangat Bagus \\
\hline
\end{tabular}

Penjelasan Tabel 16 :

a. Nilai throughtput baik PPTP maupun L2TP pada percobaan pertama dan kedua masuk kedalam kategori sedang.

b. Nilai delay PPTP dan L2TP pada percobaan pertama dan kedua masuk kategori sangat bagus, yang berarti delay kedua protokol ini rendah.

c. Nilai packet loss pada kedua protokol baik PPTP maupun L2TP masuk kedalam category sangat bagus, dimana selama pengujian tidak menunjukkan adanya paket yang hilang.

Tabel 17. Perbandingan Nilai Parameter QoS

\begin{tabular}{|c|c|c|c|}
\hline \multirow{2}{*}{ No } & \multirow{2}{*}{ Parameter QoS } & \multicolumn{2}{|c|}{ PPTP } \\
\cline { 3 - 4 } & & Percobaan 1 & Percobaan 2 \\
\hline 1 & Throughtput & $48,96 \%$ & $35,24 \%$ \\
\hline 2 & Delay & $12,39 \mathrm{~ms}$ & $15,992 \mathrm{~ms}$ \\
\hline 3 & Packet Loss & $0 \%$ & $0 \%$ \\
\hline \multirow{2}{*}{ No } & \multirow{2}{*}{ Parameter QoS } & \multicolumn{2}{|c|}{ L2TP } \\
\cline { 3 - 4 } & & Percobaan 1 & Percobaan 2 \\
\hline 1 & Throughtput & $31,13 \%$ & $26,09 \%$ \\
\hline 2 & Delay & $21,15 \mathrm{~ms}$ & $24,65 \mathrm{~ms}$ \\
\hline 3 & Packet Loss & $0 \%$ & $0 \%$ \\
\hline
\end{tabular}

Penjelasan Tabel 17 :

a. Nilai throughtput PPTP pada percobaan pertama lebih besar dibandingkan L2TP yang berarti kecepatan transfer data PPTP lebih unggul dibandingkan L2TP.

b. Nilai delay PPTP pada percobaan pertama lebih rendah dibandingkan L2TP yang berati waktu jeda PPTP lebih singkat dibandingkan L2TP sehingga paket lebih cepat untuk dikirim oleh server.

c. Nilai packet loss pada kedua protokol tidak menunjukkan adanya paket yang hilang selama pengamatan berlangsung.

d. Nilai throughtput PPTP pada percobaan kedua juga lebih besar dibandingkan L2TP yang berarti kecepatan transfer data PPTP lebih unggul dibandingkan L2TP, walaupun terdapat penurunan nilai dibandingkan percobaan pertama pada setiap protokol.

e. Pada percobaan kedua juga terdapat perubahan nilai delay untuk setiap protokol. Nilai delay PPTP pada percobaan kedua lebih rendah dibandingkan L2TP yang berati waktu jeda PPTP lebih singkat dibandingkan L2TP sehingga paket lebih cepat untuk dikirim oleh server.

f. Nilai packet loss pada kedua protokol tidak menunjukkan adanya paket yang hilang selama pengamatan berlangsung.

\section{Kesimpulan}

1. Masing - masing parameter pada setiap percobaan menunjukkan kualitas yang sama. Tetapi perbedaan terdapat pada nilai masing - masing parameter QoS.

2. Parameter delay menunjukkan hasil bahwa PPTP memiliki waktu delay yang lebih singkat dibandingkan dengan L2TP.

3. Pada parameter throughtput, PPTP memiliki nilai yang lebih besar dibandingkan L2TP di setiap percobaan.

4. Pada packet loss, baik PPTP maupun tidak terdapat paket yang hilang.

5. Kinerja protokol PPTP pada jaringan VPN lebih baik dari protokol L2TP dari pengujian sisi Quality of Service $(\mathrm{QoS})$ yang dilakukan. 


\section{Daftar Pustaka}

Budiadji, Asrul. 2009. Simulasi Untuk Membandingkan Kinerja PPTP Dan L2TP Untuk Berbagai Kelas Trafik. Depok.

hisham, https://hisham.id/2019/03/pengertiantunneling.html, diakses tanggal 4 Agustus 2019.

Onno, W Purbo., Kresno, Aji. 2000. Buku Pintar Keamanan Jaringan Internet. Jakarta. Elex Media Komputindo.

Prihatin Oktivasari \& Andri Budhi Utomo, 2016, Analisa Virtual Private Network Menggunakan OpenVPN Dan Point To Point Tunneling Protocol.

Towidjojo, Rendra., 2013, Mikrotik KungFu, Jasakom. Jakarta.

Towidjojo, Rendra. 2015. Mikrotik Kungfu Kitab 3. Jakarta : Jasakom.

Yanto. 2013. Analisis QoS (Quality of Service) pada jaringan internet (Study Kasus Fakultas Teknik Untan) : Pontianak. 